Dieses Dokument ist eine Zweitveröffentlichung (Postprint) /

This is a self-archiving document (accepted version):

M. Hoffmann, B. Max, T. Mittmann, U. Schroeder, S. Slesazeck, T. Mikolajick

Demonstration of High-speed Hysteresis-free Negative Capacitance in Ferroelectric Hfo.5Zro.502

Erstveröffentlichung in / First published in:

IEEE International Electron Devices Meeting (IEDM). San Francisco, 01.- 05. Dez. 2018. IEEE, S. 727-730. ISBN 978-1-7281-1987-8

DOI: https://doi.org/10.1109/IEDM.2018.8614677

Diese Version ist verfügbar / This version is available on:

https://nbn-resolving.org/urn:nbn:de:bsz:14-qucosa2-769141 


\title{
Demonstration of High-speed Hysteresis-free Negative Capacitance in Ferroelectric $\mathrm{Hf}_{0.5} \mathrm{Zr}_{0.5} \mathrm{O}_{2}$
}

\author{
M. Hoffmann ${ }^{1}$, B. Max ${ }^{1,2}$, T. Mittmann ${ }^{1}$, U. Schroeder ${ }^{1}$, S. Slesazeck ${ }^{1}$, and T. Mikolajick ${ }^{1,2}$ \\ ${ }^{1}$ NaMLab gGmbH, Noethnitzer Str. 64, 01187 Dresden, Germany, email: michael.hoffmann@,namlab.com \\ ${ }^{2}$ Chair of Nanoelectronic Materials, TU Dresden, Dresden, Germany
}

\begin{abstract}
We report the experimental observation of hysteresis-free negative capacitance (NC) in thin ferroelectric $\mathrm{Hf}_{0.5} \mathrm{Zr}_{0.5} \mathrm{O}_{2}$ (HZO) films through high-speed pulsed chargevoltage measurements. Hysteretic switching is suppressed by the addition of thin $\mathrm{Al}_{2} \mathrm{O}_{3}$ layers on top of the $\mathrm{HZO}$ to prevent the screening of the polarization. We observe an S-shaped polarization-electric field dependence without hysteresis in agreement with Landau theory, which enables direct extraction of NC modeling parameters for ferroelectric HZO. Hysteresis-free $\mathrm{NC}$ is demonstrated down to $100 \mathrm{~ns}$ pulse widths limited only by our measurement setup. These results give critical insights into the physics of ferroelectric NC and practical NC device design using ferroelectric HZO.
\end{abstract}

\section{INTRODUCTION}

To overcome the fundamental limits of power dissipation in nanoscale transistors due to the minimum subthreshold swing $S>60 \mathrm{mV} / \mathrm{dec}$ at room temperature, several new device concepts have been proposed, e.g. the tunnel-FET and the negative capacitance (NC) FET [1]. The latter is based on the idea that ferroelectric materials exhibit an S-shaped polarization-electric field $(P-E)$ dependence, which implies a region of $\mathrm{NC}$ (i.e. $C_{\mathrm{F}}<0$ ) without hysteresis according to Landau theory (see the red line in Fig. 1). However, in typical ferroelectric devices, large hysteresis and only positive capacitance $C_{\mathrm{F}}>0$ is observed as shown in the blue line in Fig. 1. To obtain the S-shaped $P-E$ curve, it is necessary to add a dielectric (or semiconducting) layer in contact to the ferroelectric, to prevent the immediate screening of its spontaneous polarization $P_{\mathrm{S}}[2]$. For hysteresis-free operation, the capacitance $C_{\mathrm{D}}$ of this dielectric layer must be matched to the ferroelectric $\mathrm{NC}$ region $\left(C_{\mathrm{D}}<\left|C_{\mathrm{F}}\right|\right)$, see Fig. 1. The most promising ferroelectrics for NCFET applications are $\mathrm{HfO}_{2}$ and $\mathrm{ZrO}_{2}$ based materials due to their full CMOS process compatibility and high scalability [3]. Especially the equal mixture of $\mathrm{Hf}_{0.5} \mathrm{Zr}_{0.5} \mathrm{O}_{2}(\mathrm{HZO})$ shows good ferroelectric properties even for thinner films and lower thermal budget integration. While NCFETs with $S<60$ $\mathrm{mV} / \mathrm{dec}$ and without hysteresis have been demonstrated using DC measurements [4], all reports of faster or even pulsed measurements have shown considerable hysteresis so far. Therefore, an unambiguous demonstration of hysteresis-free $\mathrm{NC}$ in HZO even during fast pulsed operation (which corresponds to the actual operating condition in a digital circuit) is urgently needed. To experimentally show this, here we fabricated capacitors using ferroelectric $\mathrm{HZO}$ with and without dielectric $\mathrm{Al}_{2} \mathrm{O}_{3}$ layers on top. We also varied the thickness of both $\mathrm{HZO}$ and $\mathrm{Al}_{2} \mathrm{O}_{3}$ layers to investigate the scalability of the
$\mathrm{NC}$ effect as well as capacitance mismatch $\left(C_{\mathrm{D}}>\left|C_{\mathrm{F}}\right|\right)$ and charge trapping, which can give rise to undesirable hysteresis. By using a pulsed charge-voltage $(Q-V)$ measurement approach [5], we can distinguish between $\mathrm{NC}$ and hysteretic switching and examine the speed limits of hysteresis-free NC in HZO. Furthermore, from the pulsed $Q-V$ data we can reconstruct the S-shaped $P-E$ curve and thus directly extract the Landau parameters for $\mathrm{HZO}$, which are crucial for accurate NCFET device modeling.

\section{EXPERIMENTAL}

Metal-ferroelectric-metal (MFM) and metal-ferroelectricinsulator-metal (MFIM) capacitors were fabricated on Si substrates. TiN bottom electrodes of $12 \mathrm{~nm}$ thickness were reactively sputtered in a BESTEC physical vapor deposition tool at room temperature. Subsequently, $7.7 \mathrm{~nm}$ and $11.3 \mathrm{~nm}$ thin HZO films were grown by atomic layer deposition (ALD) in an Oxford Instruments OpAL ALD tool at $260^{\circ} \mathrm{C}$ using the precursors TEMA-Hf, and TEMA-Zr with water as an oxidant. For MFIM samples, ALD of $0.5 \mathrm{~nm}$ to $4 \mathrm{~nm} \mathrm{Al}_{2} \mathrm{O}_{3}$ was carried out directly after HZO deposition without breaking vacuum using TMA and water as precursors also at $260^{\circ} \mathrm{C}$. The film thicknesses were adjusted by varying the number of ALD cycles. TiN top electrodes were deposited in the same way as the bottom electrodes. The HZO layers were then crystallized by $600{ }^{\circ} \mathrm{C}$ annealing for $20 \mathrm{~s}$ in $\mathrm{N}_{2}$ atmosphere. Capacitor pads were defined by evaporating $10 \mathrm{~nm} \mathrm{Ti}$ and $30 \mathrm{~nm}$ Pt through a shadow mask. These Pt dots $\left(\sim 7000 \mu \mathrm{m}^{2}\right)$ served as a hard mask during the wet etch $\left(\mathrm{NH}_{4} \mathrm{OH}, \mathrm{H}_{2} \mathrm{O}_{2}\right.$, and $\mathrm{H}_{2} \mathrm{O}$ solution) of the TiN top electrode. Similarly, TiN $/ \mathrm{Al}_{2} \mathrm{O}_{3} / \mathrm{TiN}$ reference capacitors were fabricated to extract the relative permittivity $\varepsilon_{\mathrm{r}}=8$ of the $\mathrm{Al}_{2} \mathrm{O}_{3}$. X-ray reflectometry and grazing-incidence X-ray diffraction (GIXRD) measurements were carried out on a Bruker D8 Discover $(\mathrm{Cu}-\mathrm{K} \alpha$ radiation, $\lambda=$ $0.154 \mathrm{~nm}$ ) for structural analysis of the samples. Transmission electron microscopy (TEM) analysis was carried out on a Zeiss Libra 200 TEM. Electrical measurements were performed on a Cascade Microtech Probe Station with a Keithley 4200 SCS with a 4225-PMU and remote amplifier, an HP 8110A pulse generator and a Tektronix TDS7154B digital oscilloscope. Standard polarization-electric field hysteresis was measured by applying triangular voltage signals with 10 $\mathrm{kHz}$ frequency. Capacitance-voltage measurements were carried out using a small-signal amplitude of $50 \mathrm{mV}$ and a frequency of $10 \mathrm{kHz}$. For pulsed charge-voltage measurements, capacitors were connected to the pulse generator while measuring the current and voltage via the oscilloscope with a $50 \Omega$ and $1 \mathrm{M} \Omega$ input impedance, respectively. 


\section{RESUltS AND DISCUSSION}

To confirm ferroelectricity in our HZO films we first used GIXRD to determine their crystalline structure. As shown in Fig. 2, both $7.7 \mathrm{~nm}$ and $11.3 \mathrm{~nm}$ thin HZO films mainly consist of the ferroelectric orthorhombic phase. The electrical measurements of the fabricated MFM capacitors in Fig. 3 show excellent ferroelectric properties with coercive fields of $\sim 1 \mathrm{MV} / \mathrm{cm}$ and a high remanent polarization $P_{\mathrm{r}}$ of up to 27 $\mu \mathrm{C} / \mathrm{cm}^{2}$ after $10^{5}$ electric field cycles. Furthermore, symmetric butterfly-shaped capacitance-field characteristics (Fig. 4) and only small $P_{\mathrm{r}}$ changes with electric field cycling are observed (Fig. 5). To investigate the NC behavior of these HZO layers, we fabricated and characterized MFIM structures with dielectric $\mathrm{Al}_{2} \mathrm{O}_{3}$ layers of $0.5 \mathrm{~nm}$ to $4 \mathrm{~nm}$ thickness. Fig. 6 shows a TEM cross-section of an MFIM capacitor with $7.7 \mathrm{~nm} \mathrm{HZO}$ and $4 \mathrm{~nm} \mathrm{Al} \mathrm{Al}_{2} \mathrm{O}_{3}$ to confirm the thickness of the individual layers. In the higher resolution TEM cross-section in Fig. 7, the polycrystalline nature of the HZO layer in contrast to the amorphous structure of $\mathrm{Al}_{2} \mathrm{O}_{3}$ can be seen. For all combinations of layer thicknesses $(7.7 \mathrm{~nm} / 11.3 \mathrm{~nm}$ HZO and $0.5-4 \mathrm{~nm}$ $\mathrm{Al}_{2} \mathrm{O}_{3}$ ) we carried out small-signal capacitance measurements to look for a capacitance enhancement $C>C_{\mathrm{D}}$, which would indirectly prove $\mathrm{NC}$ in the $\mathrm{HZO}$ layer. The inverse capacitances $C^{-1}$ are plotted as a function of the $\mathrm{Al}_{2} \mathrm{O}_{3}$ thickness in Fig. 8 . As can be seen, no small-signal capacitance enhancement is observed for the MFIM layers. In fact, the $\mathrm{HZO}$ and $\mathrm{Al}_{2} \mathrm{O}_{3}$ layers behave exactly as two positive capacitors in series where $C^{-1}=C_{\mathrm{D}}{ }^{-1}+C_{\mathrm{F}}^{-1}$. This means that no stabilized $\mathrm{NC}$ is observed in these structures, which seems to be related to fixed charges at the $\mathrm{HZO} / \mathrm{Al}_{2} \mathrm{O}_{3}$ interface that screen the remanent polarization when no voltage is applied [5]. Therefore, pulsed $Q-V$ measurements were necessary to access the ferroelectric NC region during switching. Using a pulse generator and oscilloscope, the applied voltage and current flowing were measured (see setup in Fig. 9), from which the charge on the capacitor was calculated. Fig. 10 shows the results of such a pulsed measurement on a $11.3 \mathrm{~nm} \mathrm{HZO} / 4 \mathrm{~nm} \mathrm{Al}_{2} \mathrm{O}_{3}$ capacitor: In (a) the applied voltage waveform $V_{1}$ is shown with a pulse width of $\sim 500 \mathrm{~ns}$ and increasing amplitude. In (b), the measured current $I$ is shown during charging and discharging of the capacitor. From the integration of $I$, the charge is obtained, and maximum, released and residual charges are defined in Fig. 10(c) as $Q_{\max }, Q_{\mathrm{D}}$ and $Q_{\text {res }}$, respectively. These charges are plotted against the maximum applied voltage $V_{1, \max }$ in Fig. $10(\mathrm{~d})$. Note that the released charge $Q_{\mathrm{D}}$ for higher voltages is larger than the charge expected for a $4 \mathrm{~nm} \mathrm{Al}_{2} \mathrm{O}_{3}$ layer only, which means that the capacitance of the $\mathrm{HZO}$ layer $C_{\mathrm{F}}$ must be negative in this region [5]. The field in the HZO layer is given by $E_{\mathrm{F}}=\left(V_{1, \max }-Q_{\mathrm{D}} / C_{\mathrm{D}}-R I\right) / t_{\mathrm{F}}$, where $R$ is the resistance and $t_{\mathrm{F}}$ the ferroelectric thickness. If we plot $E_{\mathrm{F}}$ as a function of $Q_{\mathrm{D}} \approx$ $P$, we obtain the HZO $P-E_{\mathrm{F}}$ curve shown in Fig. 11. A region of NC is observed which starts for positive applied pulses $V_{1}$ around the coercive field of $\sim 1 \mathrm{MV} / \mathrm{cm}$. For negative applied pulses, only a linear dielectric response is observed, which shows that the $\mathrm{HZO}$ is initially in the negative $P_{\mathrm{r}}$ state due to compensating charges at the $\mathrm{HZO} / \mathrm{Al}_{2} \mathrm{O}_{3}$ interface. Using Landau theory $\left(E_{\mathrm{F}}=2 \alpha P_{\mathrm{S}}+4 \beta P_{\mathrm{S}}{ }^{3}\right.$ and $\left.Q_{\mathrm{D}}=\varepsilon_{0} \varepsilon_{\mathrm{b}} E_{\mathrm{F}}+P_{\mathrm{S}} \approx P\right)$, we obtain an excellent agreement to the experimental data ( $\alpha$ $=-8.8 \cdot 10^{8} \mathrm{~m} / \mathrm{F}, \beta=1.3 \cdot 10^{10} \mathrm{~m}^{5} /\left(\mathrm{C}^{2} \mathrm{~F}\right)$ and $\left.\varepsilon_{\mathrm{b}}=25\right)$. Note that the $P_{\mathrm{r}} \approx 18 \mu \mathrm{C} / \mathrm{cm}^{2}$ is in good agreement with the values in Fig. 5 for the pristine sample. To confirm that this NC effect is hysteresis-free, we applied $500 \mathrm{~ns}$ ascending and descending pulses to the MFIM samples with $4 \mathrm{~nm} \mathrm{Al}_{2} \mathrm{O}_{3}$ which is shown in Fig. 12. Fig. 13 shows the extracted $P$ - $E_{\mathrm{F}}$ curve for the 7.7 $\mathrm{nm}$ HZO sample, which confirms the absence of hysteretic switching. Again, Landau theory can nicely fit the measured results $\left(\alpha=-1.1 \cdot 10^{9} \mathrm{~m} / \mathrm{F}, \beta=2.5 \cdot 10^{10} \mathrm{~m}^{5} /\left(\mathrm{C}^{2} \mathrm{~F}\right)\right.$ and $\left.\varepsilon_{\mathrm{b}}=25\right)$. To investigate hysteresis as a function of $\mathrm{Al}_{2} \mathrm{O}_{3}$ thickness, we repeated the experiment for the other MFIM samples. As exemplarily shown in Fig. 14, for $1 \mathrm{~nm} \mathrm{Al}_{2} \mathrm{O}_{3}$ and $7.7 \mathrm{~nm}$ $\mathrm{HZO}$, a hysteresis in the $Q_{\mathrm{D}}-V_{1, \max }$ characteristics emerges which is related to the capacitance mismatch $C_{\mathrm{D}}>\left|C_{\mathrm{F}}\right|$ of both layers. The maximum $Q_{\mathrm{D}}$-hysteresis $\Delta Q_{\mathrm{D}}$ is plotted as a function of the $\mathrm{Al}_{2} \mathrm{O}_{3}$ thickness in Fig. 15. For $\mathrm{Al}_{2} \mathrm{O}_{3}$ layers thinner than $\sim 1.8 \mathrm{~nm}, C_{\mathrm{D}}>\left|C_{\mathrm{F}}\right|$ which results in a large hysteresis. For 2-3 nm $\mathrm{Al}_{2} \mathrm{O}_{3}$ thickness (where $C_{\mathrm{D}}<\left|C_{\mathrm{F}}\right|$ ) we observe a transition region which might be related to some mismatched domains and/or charge trapping. Only for the $4 \mathrm{~nm} \mathrm{Al}_{2} \mathrm{O}_{3}$ sample, negligible hysteresis is observed since all domains are matched and charge trapping is completely inhibited. To investigate the speed of $\mathrm{NC}$ in $\mathrm{HZO}$, we shortened the pulse widths down $100 \mathrm{~ns}$, where we still observed NC effects without hysteresis as shown in Fig. 16. For future work, investigations on the relation between fundamental switching kinetics [6] and $\mathrm{NC}$ observed in $\mathrm{HfO}_{2}$ based ferroelectrics will be of interest. Lastly, Fig. 17 compares all hysteresis-free NC reports of MFIM devices from literature. While prior works used thicker perovskite ferroelectrics, this work demonstrates the superior scalability of $\mathrm{HfO}_{2}$ based materials with the additional advantage of full CMOS process compatibility.

\section{Conclusions}

Hysteresis-free $\mathrm{NC}$ in $\mathrm{HZO} / \mathrm{Al}_{2} \mathrm{O}_{3}$ stacks has been demonstrated down to $100 \mathrm{~ns}$ short pulsed voltage operation. Sshaped $P-E$ curves for direct fitting of Landau coefficients were extracted. For thinner $\mathrm{Al}_{2} \mathrm{O}_{3}$ films, increased hysteresis was observed. These results highlight pathways towards fast and hysteresis-free $\mathrm{NC}$ devices for digital applications.

\section{ACKNOWLEDGMENT}

This work has received funding from the Electronic Component Systems for European Leadership (ECSEL) Joint Undertaking under grant agreement No 692519. ECSEL receives support from the EU's Horizon 2020 research and innovation programme and Belgium, Germany, France, Netherlands, Poland, United Kingdom. Part of this work was supported by the EFRE fund of the European Commission and by the Free State of Saxony. We gratefully acknowledge U. Mühle of Fraunhofer IKTS for TEM analysis.

\section{REFERENCES}

[1] S. Salahuddin and S. Datta, Nano Lett., vol. 8, pp. 405-410, 2008.

[2] P. Zubko et al., Nature, vol. 534, pp. 524-528, 2016.

[3] J. Müller et al., Nano Lett., vol. 12, pp. 4318-4323, 2012.

[4] M. Si et al., Nat. Nanotechnol., vol. 13, pp. 24-28, 2018.

[5] Y. J. Kim et al., Nano Lett., vol. 16, pp. 4375-4381, 2016.

[6] H. Mulaosmanovic et al., ACS Appl. Mater. Interfaces, vol. 9, pp. 37923798, 2017. 


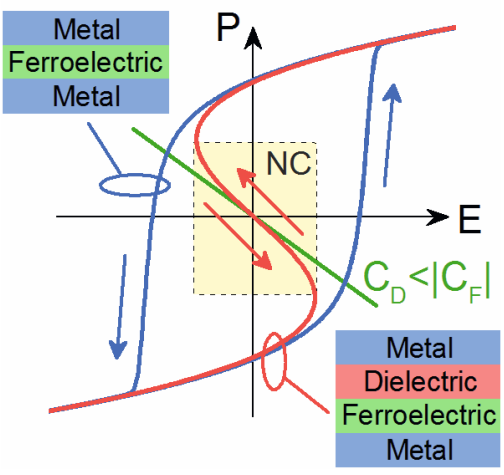

Fig. 1. Polarization-electric field $(P-E)$ dependence of a ferroelectric based on Landau theory. Without dielectric, hysteresis and only positive capacitance $C_{\mathrm{F}}$ is expected while with dielectric, no hysteresis and negative capacitance $(\mathrm{NC}) C_{\mathrm{F}}<0$ is achieved, if the dielectric capacitance $C_{\mathrm{D}}$ is matched in the $\mathrm{NC}$ region, i.e. $C_{\mathrm{D}}<\left|C_{\mathrm{F}}\right|$ (see green load line of the dielectric).

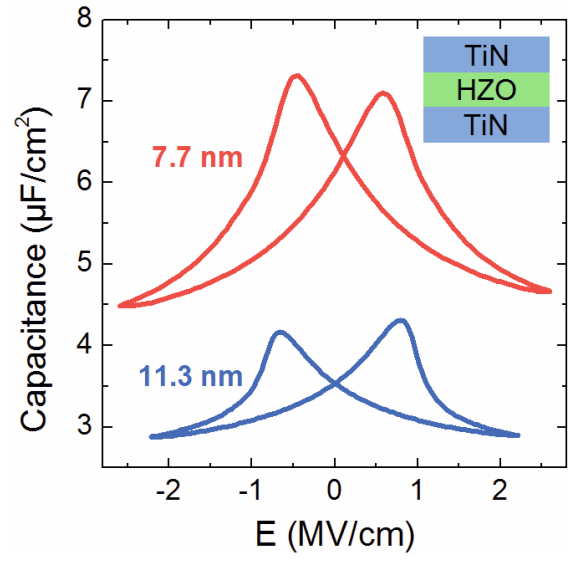

Fig. 4. Capacitance-electric field hysteresis for different HZO thicknesses measured at the frequency $f=10 \mathrm{kHz}$ and $50 \mathrm{mV}$ small-signal amplitude after wake-up cycling $\left(10^{5}\right.$ cycles at 100 $\mathrm{kHz})$.

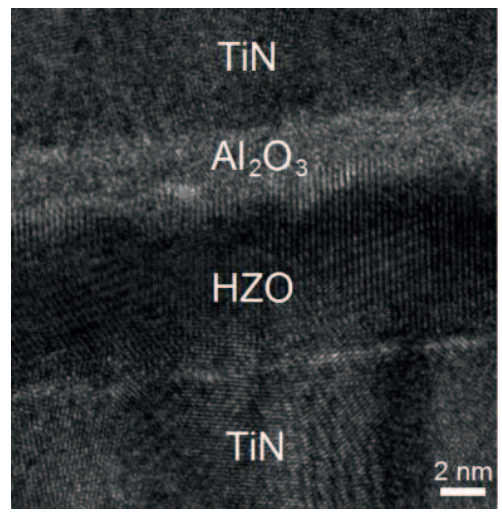

Fig. 7. High-resolution TEM of the $4 \mathrm{~nm}$ $\mathrm{Al}_{2} \mathrm{O}_{3}$ and $7.7 \mathrm{~nm} \mathrm{HZO}$ capacitor. The polycrystalline structure of $\mathrm{HZO}$ and amorphous phase of the $\mathrm{Al}_{2} \mathrm{O}_{3}$ layer can be seen.

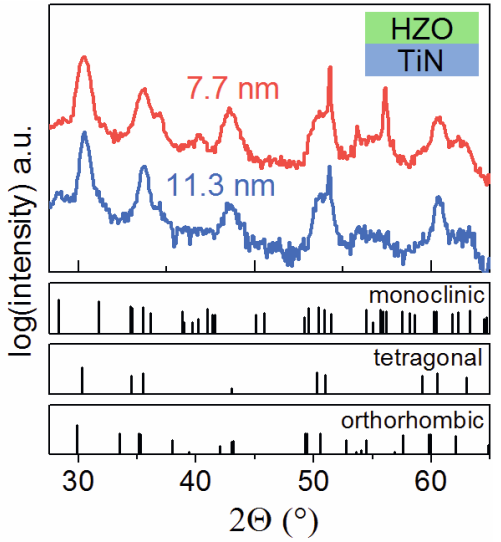

Fig. 2. Grazing-incidence X-ray diffraction patterns of ferroelectric HZO layers of different thickness compared to reference patterns for common phases in $\mathrm{HfO}_{2}$. The $\mathrm{HZO}$ films are mostly orthorhombic.

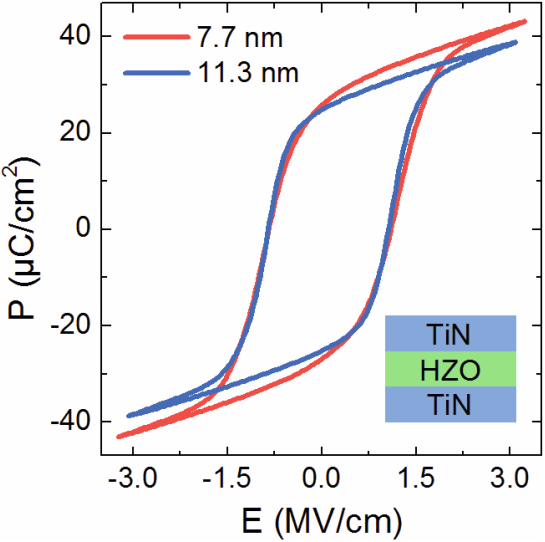

Fig. 3. Experimental $P-E$ hysteresis curves measured at $10 \mathrm{kHz}$ for $\mathrm{TiN} / \mathrm{HZO} / \mathrm{TiN}$ capacitors with different HZO thicknesses after wakeup cycling $\left(10^{5}\right.$ cycles at $\left.100 \mathrm{kHz}\right)$.

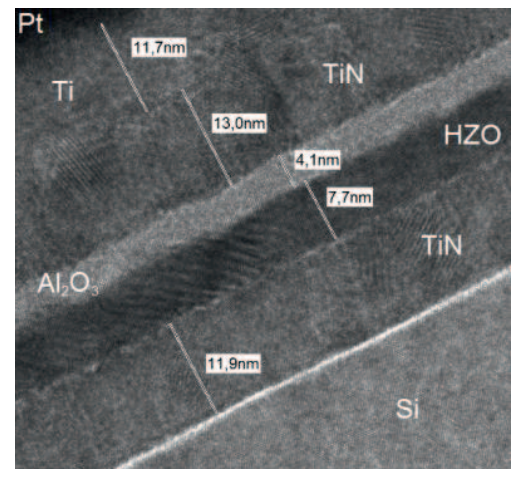

Fig. 6. Transmission electron microscope (TEM) cross-section of an $\mathrm{Al}_{2} \mathrm{O}_{3} / \mathrm{HZO}$ capacitor structure with about $4 \mathrm{~nm} \mathrm{Al}_{2} \mathrm{O}_{3}$ and $7.7 \mathrm{~nm} \mathrm{HZO}$

Fig. 5. Evolution of remanent polarization $P_{\mathrm{r}}$ with electric field cycling $(f=100 \mathrm{kHz})$ for different HZO thicknesses.

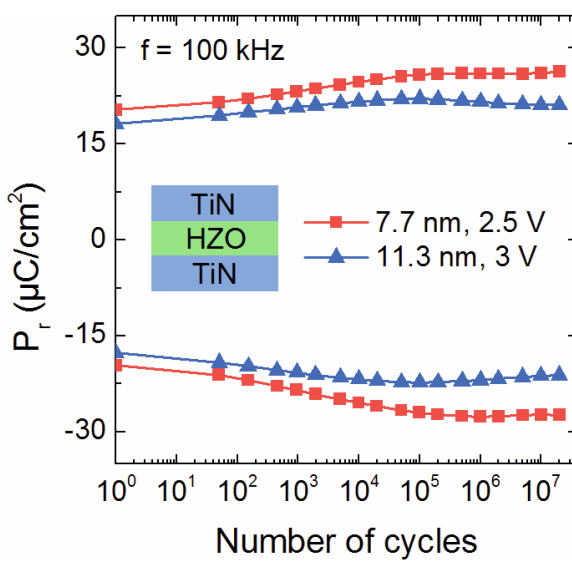

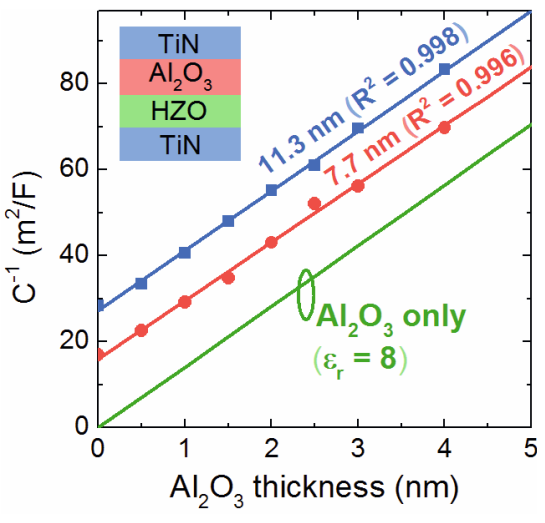

Fig. 8. Inverse small-signal capacitance $C$ ( $f=10 \mathrm{kHz}, 50 \mathrm{mV}$ amplitude) for different $\mathrm{HZO}$ and $\mathrm{Al}_{2} \mathrm{O}_{3}$ thicknesses. Solid blue and red lines show linear fits and the green line corresponds to the theoretical capacitance of $\mathrm{Al}_{2} \mathrm{O}_{3}$ without $\mathrm{HZO}$.

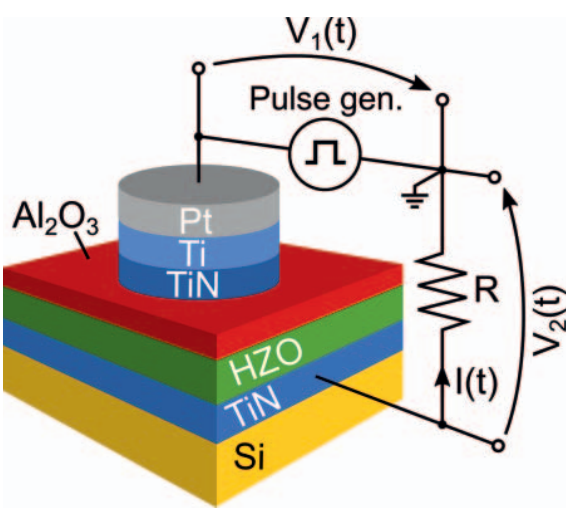

Fig. 9. Schematic sample structure and experimental setup for pulsed charge-voltage measurements. Short voltage pulses are applied to the top electrode while the current is measured through the $50 \Omega$ input resistance of an oscilloscope. The pulse voltage is measured at the same time. 

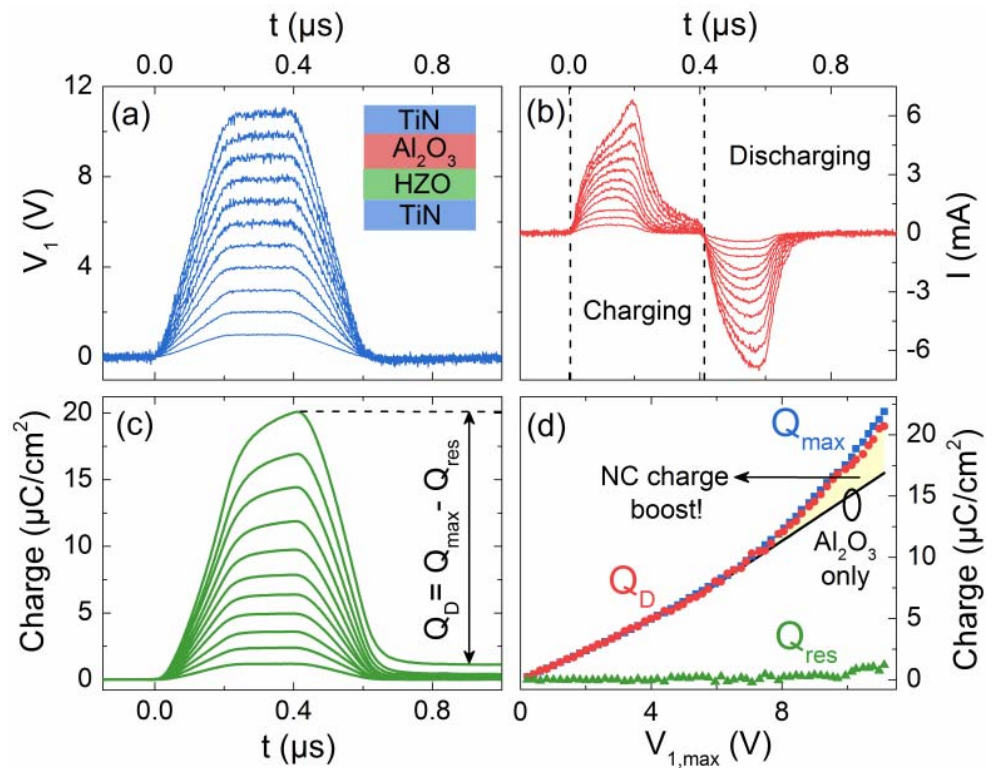

Fig. 10. (a) Applied voltage pulses with increasing amplitude. (b) Measured current during charging and discharging of the $11.3 \mathrm{~nm} \mathrm{HZO} / 4 \mathrm{~nm} \mathrm{Al}_{2} \mathrm{O}_{3}$ capacitor. (c) Charge on the capacitor as a function of time $t$ integrated from the current in (b). (d) Maximum, released and residual charges $\left(Q_{\max }\right.$, $Q_{\mathrm{D}}$ and $\left.Q_{\mathrm{res}}\right)$ as a function of maximum applied voltage. Black line shows expected charge for $4 \mathrm{~nm}$ $\mathrm{Al}_{2} \mathrm{O}_{3}$ layer without $\mathrm{HZO}$.

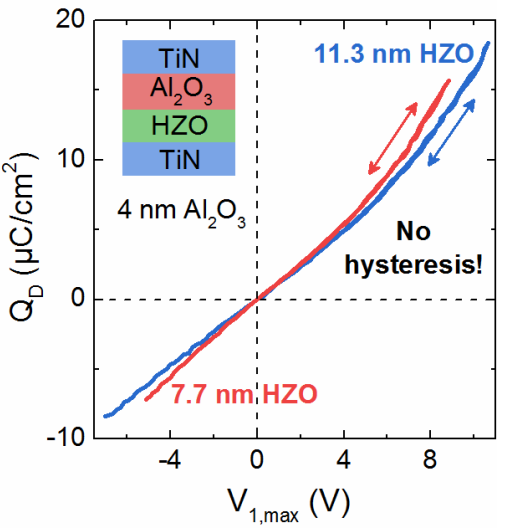

Fig. 12. Pulsed charge-voltage hysteresis measurement for capacitors with $4 \mathrm{~nm} \mathrm{Al}_{2} \mathrm{O}_{3}$. No hysteresis is observed for ascending and descending voltage pulse trains with $500 \mathrm{~ns}$ pulse width.

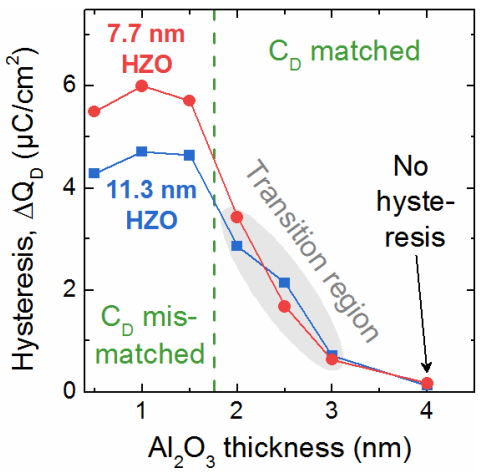

Fig. 15. Maximum hysteresis as a function of layer thicknesses. For $\mathrm{Al}_{2} \mathrm{O}_{3}$ layers thicker than $3 \mathrm{~nm}$, no hysteresis is observed in the pulsed charge-voltage measurements with pulse widths of 500 ns. The transition region is due to partial domain mismatch and/or charge trapping effects.

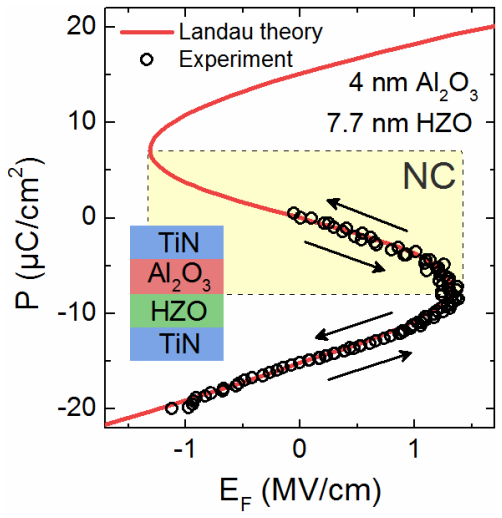

Fig. 13. Extracted $P-E$ curve for $7.7 \mathrm{~nm} \mathrm{HZO}$ with $4 \mathrm{~nm} \mathrm{Al} \mathrm{O}_{3}$ from Fig. 12. No hysteresis is observed in the S-shaped curve in accordance with fundamental Landau theory.

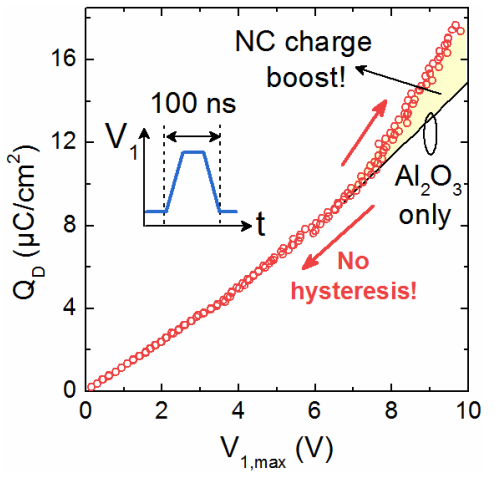

Fig. 16. Shortest applied pulses of $100 \mathrm{~ns}$ still show hysteresis-free NC in the $11.3 \mathrm{~nm}$ $\mathrm{HZO} / 4 \mathrm{~nm} \quad \mathrm{Al}_{2} \mathrm{O}_{3}$ sample. Applying even shorter pulses was not possible due to the $R C$ delay of the measurement setup $(R C \approx 30 \mathrm{~ns})$.

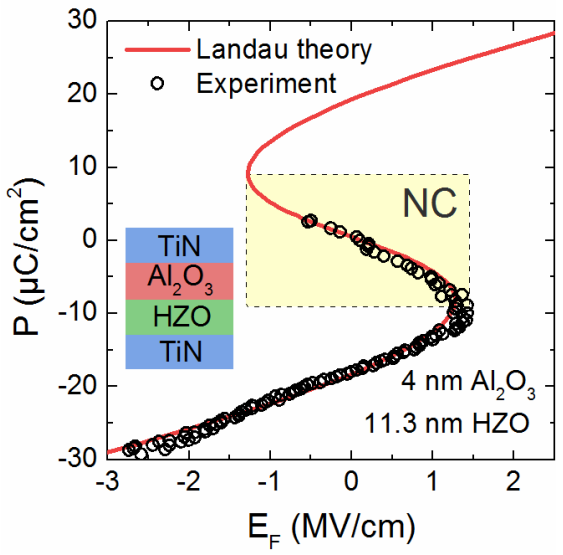

Fig. 11. Ferroelectric $P$ - $E$ curve of $11.3 \mathrm{~nm} \mathrm{HZO}$ with $4 \mathrm{~nm} \mathrm{Al} \mathrm{O}_{2} \mathrm{O}_{3}$ extracted from the pulsed chargevoltage measurements in Fig. 10. Initially, the ferroelectric is in the negative remanent state with $P_{\mathrm{r}} \approx-18 \mu \mathrm{C} / \mathrm{cm}^{2}$. For negative applied pulses, only a linear dielectric response in observed, since the $\mathrm{HZO}$ is already switched to negative polarization. However, for positive applied pulses, the ferroelectric enters the NC region corresponding to the negative slope of the S-shaped Landau $P-E$ curve.

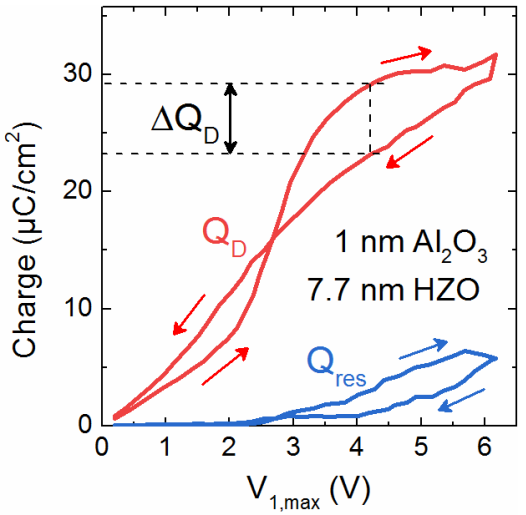

Fig. 14. Pulsed charge-voltage measurement for a capacitor with only $1 \mathrm{~nm} \mathrm{Al} \mathrm{Al}_{2} \mathrm{O}_{3}$. Hysteresis is observed due to capacitance mismatch. $\Delta Q_{\mathrm{D}}$ is defined as the maximum $Q_{\mathrm{D}}$ hysteresis.

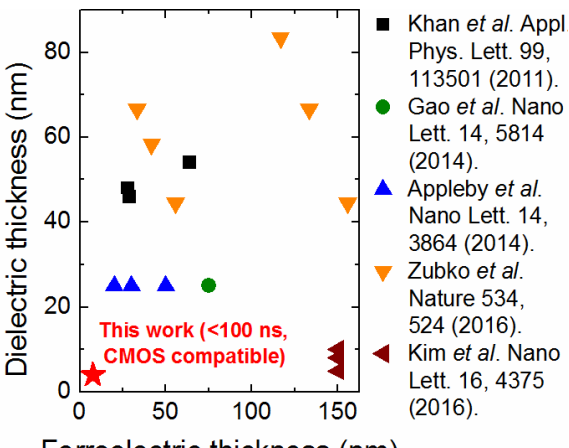

Ferroelectric thickness $(\mathrm{nm})$

Fig. 17. Comparison of hysteresis-free negative capacitance in ferroelectric/dielectric capacitors reported in literature. Besides this work, all other reports applied perovskite-based ferroelectrics which are not CMOS compatible. Additionally, $\mathrm{HZO}$ is much more scalable compared to perovskite ferroelectrics. 